\title{
DEVELOPMENT OF INDUSTRY-ORIENTED, STUDENT-CENTRED MASTER-LEVEL EDUCATION IN THE FIELD OF PHYSICAL SCIENCES IN BELARUS
}

\author{
Anatolijs Zabasta ${ }^{1}$, Nadezhda Kunicina ${ }^{1}$, Joan Peuteman ${ }^{2}$, Renaat De Craemer², \\ Alexander S. Fedotov ${ }^{3}$ \\ ${ }^{1}$ Riga Technical University, Institute of Electrical Engineering and Electronics (LATVIA) \\ ${ }^{2}$ KU Leuven, FIIW, Campus Bruges (BELGIUM) \\ ${ }^{3}$ Belarusian State University, Energy Physics Department (BELARUS)
}

\begin{abstract}
This work presents a case study of the development of industry-oriented, student-centred master-level education in the field of physical sciences in Belarus. It is important to facilitate the Bologna process in the Belarusian higher educational system facing a transition from a " $5+1$ " system (former Soviet system) to the Bologna " $4+2$ " system. The project also faces the labour market needs in the field of a number of physics specialities taking the upcoming changes into account. The approaches developed and applied in this project facilitated a creation of an integrated, logically connected system of educational methods and tools. The renewed training of master students in physical sciences is characterized by practice-oriented courses, programs and educational tools (e.g. using digital learning environments and e-books). An exchange of good practices between three European universities improved educational and linguistic competences of the Belarusian staff. Feedback from stakeholders (students, teachers, researchers, employers, labour market, a national accreditation institution) has been obtained during the entire project life cycle and has been taken into account. The new curricula are developed and adjusted according to the stakeholders' feedback in five stages: gap analysis, development of curricular, accreditation, obtaining feedback from stakeholders, analyses and adjustments.
\end{abstract}

Keywords: Bologna process, physical sciences, labour market needs, learning outcomes assessment.

\section{INTRODUCTION}

To reform the High Education System in Belarus according to the Bologna process, the Ministry of Education of Belarus requires the High Educational Institutions (HEls) to reform the curricula from the existing " $5+1$ " system to the " $4+2$ " system in order to comply with the Bologna system principles. Since academic year 2014-2015, according to a Regulation of the Ministry of Education [1] (year 2012), a part of the HEls started teaching according to a 4 years program for the first stage (bachelor degree) and an additional 2 years program for the second stage of higher education (master degree).

At the same time, for a number of physics specialities (functional nanomaterials, photonics, applied physics, nanomaterials and nanotechnologies, nanophotonics, etc.) the $5+1$ or even the $5+1.5$ systems of education did still not change in Belarus. This implies it is really necessary to realize the curricular reforms for both the first and the second stage of education (a 2-years instead of a 1 year mastership). In order to improve the education in physics, these organizational reforms of the curricula need the creation of new training programs. Due to a redistribution of learning branches between the first and second stages of education and also due to the need for practice-oriented human resources and fundamental branches of physical-mathematical sciences, new courses and educational tools are developed.

When considering the first stage of education, a reduction from 5 to 4 years may cause risks associated with the competences of the graduated students i.e. for the trained personnel for scientific research institutes, design engineering bureaus, high-tech enterprises, and universities. Graduates studying only a 4-year educational program will probably have lower qualifications than those who studied the old 5-year programs. Potential employers should take this risk into account.

Traditionally, in Belarus the amount of master-level graduates is very low (approximately $10 \%$ ) in comparison with the total amount of graduates. It is very likely that this share will grow up since employers need personnel with a qualification which is at least not lower than the qualification offered by the old 5-year training. At present, 5-year graduates mostly meet the industry and high school 
requirements. The graduates of the 6-year training cycle are mainly employed by scientific research institutes, high-tech enterprises and universities. Considering the experience gained in the European Union, the number of graduates having the entire 6-year training cycle of the "4 + 2" system should increase in order to meet the needs of universities and other employers.

Also inspired by the Bologna process, the latest version of Instruction on Workload of Higher Education Programmes Calculation via System of Credits was approved by the Ministry of Education of the Republic of Belarus in 2015. The instruction treats a credit as a numerical method to quantify the student his workload based on the achievements within his or her study program. At present, the system is already used for students who started their specialist trainings or their master degree programs after 2013. But in reality, it only has sense when realising an academic mobility. It is still not really used for students who resume their studies at their home university. The majority of the university staff and the students are still not aware about the system or do not understand its sense.

In 2015, a project "The Improvement of master-level education in the field of physical sciences in Belarusian universities (Physics)" [2], has been started in order to addresses the above mentioned problems, evolutions and challenges. The project is focused on the development of a standardized program forming the basis of modernized curricula in the field of functional nanomaterials production and photonics for all Belarusian HEls.

The project is awarded under the "Cooperation for innovation and the exchange of good practices" Program of Erasmus+. The project (http://www.physics.rtu.lv) is a collaborative initiative of three European academic institutions (the Riga Technical University (RTU), the University of Cyprus (UCY), KU Leuven University) and four Belarusian HEls (the Belarusian State University (BSU), Belarusian State Technological University (BSTU), Francisk Skorina Gomel State University (GSU), and Yanka Kupala State University of Grodno (GrSU)). The Ministry of Education of the Republic of Belarus, the Belarusian Physical Society (BPS) and the Republican Nanoindustry Association (RNIA) are nonacademic partners. The industry is presented by associated partners: the Research Institute for Nuclear Problems and a high-tech company LOTIS TII Itd.

This project aims to reform the master-level educational system in Belarusian universities in the field of applied physics, and more precisely in the field of functional nanomaterials production and nanotechnology including photonics. The RTU, more precisely the Institute of Industrial Electronics and Electrical Engineering, is the coordinator of the project.

The renewed training of master students in physical sciences is characterized by practice-oriented courses and educational tools based on a methodology explained in Section 2. Feedback from stakeholders has been obtained during the entire project life cycle and has been taken into account during the development of the new course materials. The new curricula are developed and adjusted according to the stakeholders' feedback in five stages: gap analysis, development of curricular, accreditation, obtaining feedback from stakeholders, analyses and adjustments as explained in Section 3. An exchange of good practices between three European universities improved educational and linguistic competences of the Belarusian staff (and promising students). This transfer of good practices is explained in Section 4 and it is intended to support the practical implementation of the developed course materials.

\section{METHODOLOGY}

A powerful learning environment consists of different components determining the teaching practice. Figure 1 presents a didactic model [3] which indicates the interrelationship between the learning processes, the learning outcomes, the student characteristics and the required assessments. Based on this philosophy, courses and teaching materials have been developed. All partners participated in the development of e-books and especially the course materials on "applied physics" have been integrated in digital learning environments like Blackboard and Moodle [4].

Inspired by Figure 1, during the development of the e-books and the digital learning environments, a number of principles have been taken into consideration.

- A powerful learning environment consists of different components determining the teaching practice. The learning outcomes, the student characteristics (including the diversity among the students) and the required assessments have a large impact on the learning process itself. During the course planning, the course development, the course testing and the outcome analysis this philosophy was taken into consideration. 
- The reform of the higher educational system in Belarus may cause risks associated with the competences of the graduated students. The link between the studies and the student his/her successful application at the working place can be considered as the actions that a specialist should be able to do. This principle allows to formulate the learning outcomes at the end of each study activity and at the end of the entire curriculum. Here, the feedback of employers and the opinion of a national accreditation institution are crucial.

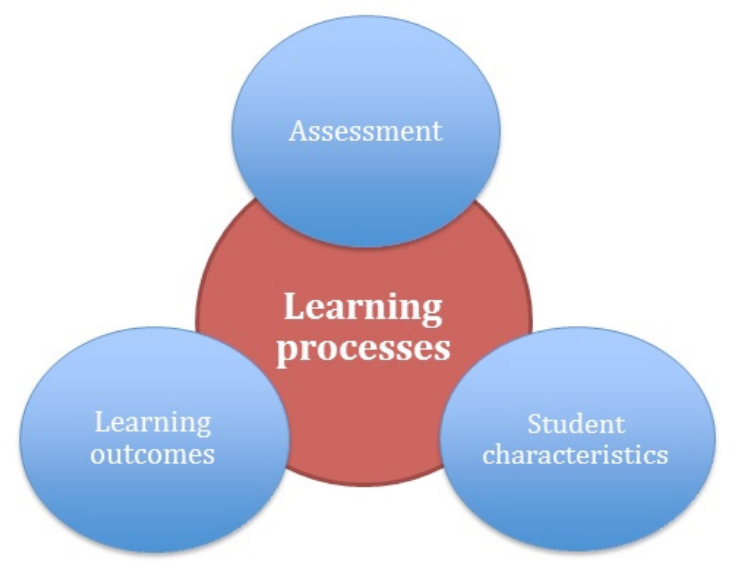

Figure 1. Components of the learning process.

- As mentioned in [4,5], the learning outcomes are narrow statements that describe what students are expected to know and be able to perform by the time of graduation. These relate to skills, knowledge and behaviors that students acquire in their matriculation through the program. The learning outcomes are important for the teacher, when taking decisions on the design of the learning environment. The assessment of outcomes includes the determination and the evaluation of the result of the learning process i.e. the achievement of the learning outcomes. The evaluation methods, having sufficient variation, must be consistent with the didactic methods and the learning activities. In practice, the assessment plays a crucial role, since teaching students adjust their learning activities to the assessment $[4,6]$.

- Usually different evaluators are involved in the evaluation process. As a consequence, this process obtains a more diverse character. Besides the teaching team, potential evaluators are: externals from the professional field, fellow students ('peer assessment'), the student himself ('self-assessment'). D. Kirkpatrick proposed a four-level evaluation model to evaluate the effectiveness of learning [7]. The fourth level of his model - the "Results" - has the objective to determine the changes in the economic activities of the company, as a result of learning. J. Phillips [8] added the fifth level to the Kirkpatrick's model evaluation: ROI (return on investment in learning). Therefore, learning outcomes evaluation by external stakeholders should be recognized as very crucial for the learning and the teaching process.

\section{IMPLEMENTATION AND EVALUATION OF THE COURSE MATERIALS}

\subsection{Feedback from stakeholders}

In this project, we developed innovative curricular promoting industry-oriented, student-centered master-level curricular in the field of physical sciences in Belarus. This approach contains an evaluation by the main stakeholders (students, teachers, researchers, employers, national accreditation institution and the Ministry of Education of Belarus) during the entire project life cycle. The curricula are developed and adjusted according to the stakeholders feedback in five stages.

- Gap analysis

- Development of new curricular

- Accreditation

- Testing and obtaining feedback from stakeholders

- Analyses and final adjustments 


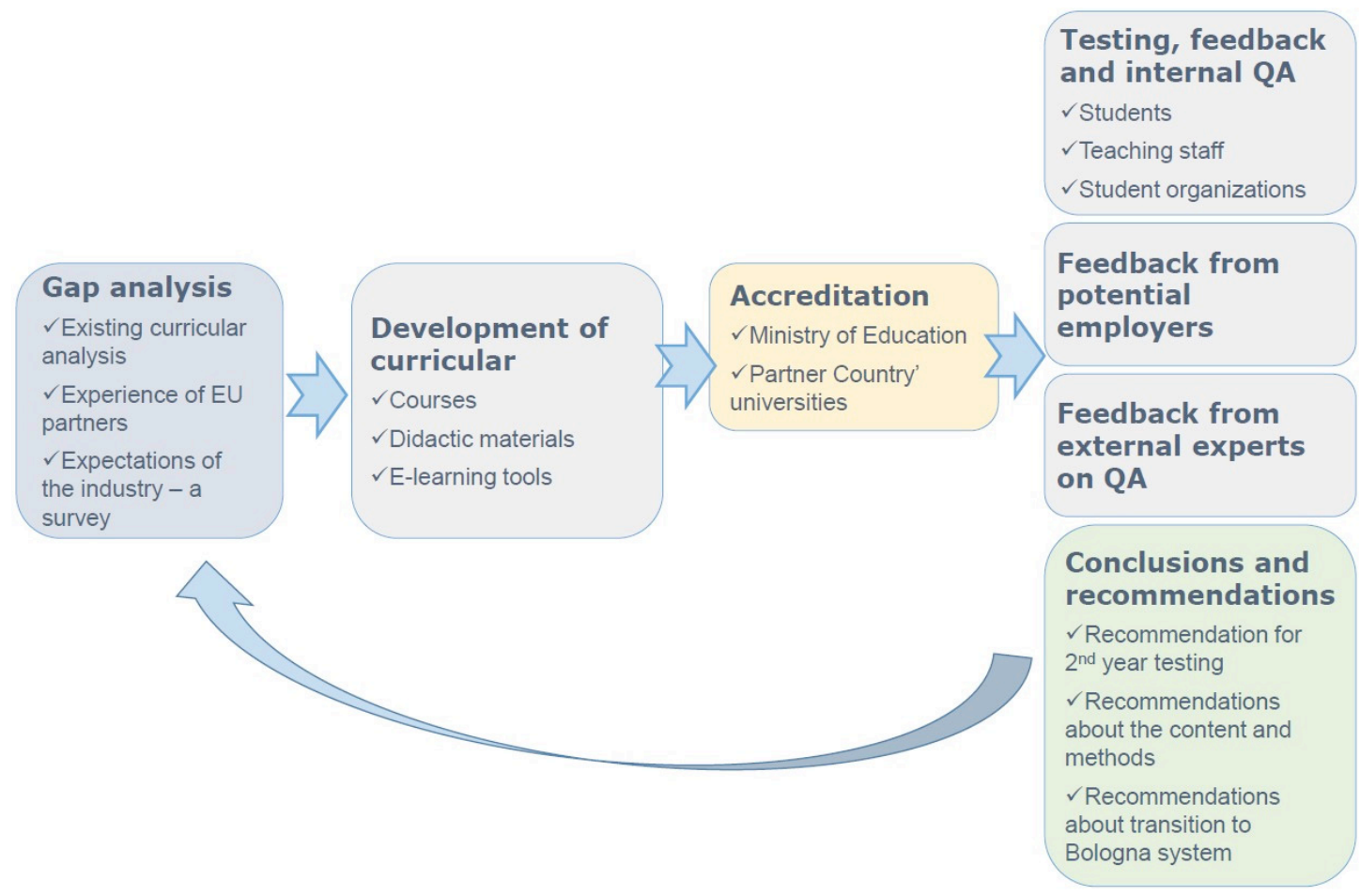

Figure 2. Feedback from stakeholders.

\subsection{Gap analysis}

In order to provide an input to the curricular development stage, we evaluated existing courses and training programs in Belarusian universities against the best practice of EU universities and provided a survey of potential employers.

To investigate the specific needs of the labour market in Belarus, a survey of professional associations, research institutes and universities as employers of master graduates has been realized as ex-ante survey in the beginning of the project in February 2016. The survey was developed using different guidelines and EU partners input, which was slightly modified taking into account the educational and cultural traditions of Belarus. The purpose of this survey was to:

- acquire ideas about the market needs of a 2-year practice-oriented master-level education;

- find out how employers judge the qualification requirements for graduates from industryoriented master programs;

- identify the training requirements of practice-oriented master programs for the planned "4 +2 " system;

- provide input to the new two-years master-level training programs "photonics" and "functional nanomaterials".

The survey involved 8 teams from 4 universities (BSU, GoSU, GrSU, BSTU), the Belarusian Physical Society, the Research Institute for Nuclear Problems of BSU and the Republican Association of NanoIndustry. The survey was divided in three logical parts. The first part is related to the industry academia secondments and the second part is devoted to the adjustment of the educational tasks to the labour market needs in this sector. The third part is dedicated to the identification of missing skills and abilities. The results of the survey have been used during the development of the curricula content for the new 2-year master students.

According to the opinions of the university teams, it is useful to carry out practice work during the last semester. This practice work can be an internship which is oriented to research activities. Its content should ensure a high scientific level of the master thesis which, in turn, should be a significant backlog for a PhD thesis. The importance of trainings in problem solving needs to increase. These recommendations differ from the existing practices where university hours are mainly dedicated to lectures. 
Related to the second group of questions, the survey results indicated which educational disciplines are needed for a successful completion of practice work and the employment of master graduates at universities, scientific research institutions and companies. Most of the respondents commonly marked disciplines associated with programming skills and specializations (75 \% of the respondents) and with theoretical physics (40\% of the respondents). Approximately $40 \%$ of the respondents have noted the importance of the acquisition of skills in measurement and automation, microcontroller system programming, group symmetry theory, etc.

Related to the identification of missing skills and abilities, some respondents noted the need to establish stable interdisciplinary connections between the blocks of mathematical, physical and special disciplines. About $75 \%$ of the respondents have noted the importance of skills like theoretical calculations, construction of mathematical models for physical processes and phenomena, programming, automation of the experiment.

The results of the survey have been used for the development of the curricula content for the 2-year master students.

\subsection{Development of new e-books and integrated courses}

Electronic course books, didactic materials (guides for laboratory works, lecture synopsises, etc.) for upgrading master-level education in the field of physical sciences (functional nanomaterials, photonics, applied physics, etc.) adjusted to labour market needs were completed and uploaded in an e-library (https://dl.bsu.by) based on the Moodle environment. The names of the e-books:

1 Applied physics;

2 Functional nanomaterials;

3 Photonics;

4 Applied informatics;

5 Research towards master thesis.

When considering the e-book on "applied physics", the course materials have been integrated in digital learning environments like Blackboard and Moodle (including multimedia materials). These course materials function as a demo-course to all participants (professors and students) [4].

Based on the e-books, resulting from a collaboration between the three European Union universities and the four Belarusian universities, new courses are integrated in the curricula of the Belarusian universities. More precisely, 11 courses are integrated at BSU, 1 course is integrated at GrSU, 9 courses are integrated at GoSU and 4 courses are integrated at BSTU master level educational programs. These new and renewed courses have been approved by the rectorates of the universities. When considering BSU, the standard master-level study programs have been approved by the Ministry of Education of the Republic of Belarus i.e.

- a 2 year master degree program on functional nanomaterials,

- a 2 year master degree program on nanomaterials and nanotechnologies.

\subsection{Testing and evaluation of integrated courses and training programs}

These new or renewed courses have also been tested in the autumn semester of academic year 2017-2018 and in the spring semester of academic year 2017-2018. The results of the autumn semester testing are already available.

Two types of questionnaire forms have been prepared: one for students and a second one for the teachers involved in course material testing. The questionnaire form for the students included 11 questions where participants were asked to rate the course material relevance, the way of teaching ... according to their perception. The relevance of each of the evaluation criteria was assessed using a Likert scale from 1 (not relevant) to 5 (very relevant). The distance between each scale point is assumed equal which implies a mark 3 represents the neutral value in this scale. A consolidated statistics form on answers given on the tested courses was elaborated by partner universities that pointed out the students their perception about the newly developed courses.

The questionnaire form for the teaching staff was mostly focused on measuring the ability of the students to acquire learning material, to pass tests and exams, and also measuring the teachers their 
perception related to the new curricula. Both students and teachers questionnaires requested to give answers to the open questions about methods of teaching, to express their opinions and suggest improvements.

The number of polled participants differed due to the number of new courses developed by universities and, of course, the total number of students in each university. For example, in BSU 72 students filled in 111 questionnaires, but Grodno University tested only one single new course implying only 8 students participated in the testing and filled in the forms [9].

The opinions of the students in the 4 Belarusian universities are quite similar i.e.

- the course materials are interesting and relevant,

- the courses have an appropriate structure,

- the practical approach of the courses is appreciated.

Especially at GoSU and at BSTU students ask for more multimedia materials like audio and video materials in order to stimulate the opportunities for self-study. The teaching staff mainly shares the opinions formulated by the students but they mention that dealing with the diversity among the prior knowledges of the students remains a challenge. Developing additional multimedia materials stimulating opportunities for self-study, as mentioned by the students, can solve the concern of the teaching staff concerning a large diversity among prior knowledges of the students.

Since the potential employers were involved in the development of new curricula throughout the whole life cycle of the project, we arranged a survey at the preparation stage of the project (see Section 3.2), and at the final stage of the project. For the project team, it was crucially to get an evaluation of the main project deliverables from the experts, who represent the industry and employers.

Therefore, the experts from the Belarusian Physical Society, the Republican Association of Nanoindustry, the Research Institute for Nuclear Problems of BSU and the Belarusian-Japanese private enterprise LOTIS-TII were interviewed about the newly developed e-books and courses. They all approved the need for the transition of the higher educational system of Belarus to the Bologna $4+2$ system. They all approved the need for the introduction of training programs in the specialities 'functional nanomaterials', 'nanomaterials and nanotechnologies' and 'photonics'. Approximately 90\% of the experts confirmed the importance of the introduced courses and laboratory work. A number of comments have been formulated to optimize the programs.

\section{INSPIRING GOOD PRACTICES}

\subsection{Training courses for the Belarusian teaching staff}

A number of training courses for the Belarusian teaching staff has been organised in order to stimulate and support the use of the developed course materials. A first training course was organised by $\mathrm{KU}$ Leuven in April 2017. The workshop focused on the use of digital learning environments, the integration of project work in an engineering curriculum, the use of electronic calculators when teaching mathematics and the integration of distance learning.

Another project target was the improvement of professional and practical English skills of the Belarusian teaching staff. A workshop on "Academic English for teachers" was organised by KU Leuven in June 2017. The workshop focused on lecturing, interacting with students and more general improving English language skills. The concept and methodology of the workshop and the incorporated practices were entirely based on Academic Spoken English, A Corpus-Based Guide to Lectures, Presentations, Seminars and Tutorials, and the electronic Lecture Board provided by the ILT (Leuven Language Institute) at KU Leuven.

A teachers training seminar was also held at RTU in February 2018. The target of the seminar was to validate the topics and methodology of the courses and training programs developed during the project as well as to discuss the first results of new courses testing in Belarusian universities during the autumn semester. Together with the teaching staff of Belarusian universities, representatives of Belarusian Nano-industry association, the Institute for Nuclear Problems and the Heat and Mass Transfer Institute also participated in discussions about the quality and relevance of new courses created in the project. A one-day session of the seminar was devoted to the active use of a digital learning environment. In the last day of the seminar, a round-table discussion was held on topics related to academia - industry collaboration. 


\subsection{Training courses for Belarusian students}

Three training courses for Belarusian students were organized: a first one in February 2016 at KU Leuven [10], faculty of Industrial Engineering Technology, a second one in October 2017 at RTU and the third one in February 2018 at the University of Cyprus. The main targets of the courses were to test teaching methodology and acquisition of the study subjects.

The training at KU Leuven focused on scientific and technological topics, related to the different areas of study and interest of the participating students. The training also focused on teaching methodology (use of ICT means, practical and lab sessions, lectures from research laboratories and lectures from an international company working in close relationship with the KU Leuven university) and on English language training. Students were hosted at the local student residence, and as thus, introduced to the students live in Flanders. The Belarusian partner universities selected 14 master degree and PhD students, following their motivation, knowledge of the English language, motivation and past study performance. A questionnaire to evaluate this training week was developed and completed by the students.

The target of the training course in RTU was the evaluation of some elements of the new courses before the start of the two years testing in Belarusian universities and to introduce a new approach that promotes innovation competences acquisition by students. This approach comprises a module of professional business-competence creation: innovations management, business organization and establishment, etc. The module was implemented through competence training, business games, practical labs, creation of roadmaps for the development of innovative products and the presentation of these roadmaps by student teams at the end of the courses. Home tasks concerning innovative products were distributed among the students as a preparation for the training course.

The training course was conducted commonly by RTU, BSU and BPS teaching staff. The Belarusian partners were presented by 16 students, and 6 professors/lectors participated simultaneously as teachers, learners and evaluators. In the first day of the training course, students were mixed and then divided to four teams using the method of Belbin Team Roles. This method should help to find and combine student strengths: talents, knowledge and skills which can be used in favour of teamwork. Each group received the task to develop an idea of a new product and to present their results at the end of the course.

At the end of the course, a survey among the students and the Belarusian teaching staff has been conducted. The relevance of the evaluation criteria was assessed using a Likert scale. We noticed that evaluation marks given by GrSU students were closer to the marks provided by the teachers. It turned out that the GrSU administration arranged a selection of the candidates for the training courses according to criterions such as English language skill, academic progress and motivation of candidates.

In February 2018, the KIOS Research and Innovation Center of Excellence (KIOS CoE) of the University of Cyprus organized a Training School for undergraduate students from Belarus. During the two-week Training School, students from all four Belarusian universities were trained on the latest technologies in power systems and renewable energy integration. The training was achieved using advanced software tools for modelling and simulation. The students also received hands-on training in state-of-the-art laboratories, as well as a technical tour to the KIOS outdoors renewable energy laboratory.

\section{CONCLUSIONS}

The methods developed and applied in this project facilitated the creation of an integrated, logically connected system of complementary educational approaches. These approaches encouraged

- to improve the training of master students in physical sciences by practice - oriented master level programmes;

- to improve competences of the teaching/technical staff of Belarusian universities.

The project encouraged Belarussian HEls to develop new courses for master-level programs and to implement an accreditation at university and national levels. Furthermore, the project provided to Belarusian HEls

- experience in the transition from the existing (former Soviet) system to a new system complying with the Bologna principles; 
- expertise in the development of master-level programs with a 2 years training cycle in the defined curricula topics;

- inspiration to collaborate with representatives of research institutions and industry for creating curricular which meet the labour market needs in the area of applied physics;

- good practices concerning the development and acquisition of innovative ICT environments, teaching tools, didactic materials dedicated to on-line and web based teaching/learning.

Feedback from stakeholders (students, teachers, researchers, employers, a national accreditation institution) obtained during all project life cycle promoted industry-oriented, student-centred masterlevel curricular in the field of physical sciences in Belarus.

\section{ACKNOWLEDGEMENTS}

The present work is supported by the Erasmus+ project "Improvement of master-level education in the field of physical sciences in Belarusian universities" having the grant $\mathrm{Nr}$ 561515-EPP-1-2015-1-LVEPPKA2-CBHE-JP-ERASMUS+.

\section{REFERENCES}

[1] The Order of the Ministry of Education of the Republic of Belarus (Приказ Министерства образования Республики Беларусь), 28.05.2012, N 389, Retrieved from URL http://naviny.org/2012/05/28/by11373.htm

[2] "The Improvement of master-level education in the field of physical sciences in Belarusian universities (Physics)", ERASMUS+, Retrieved from URL: http://physics.rtu.Iv

[3] L. Dewulf, A. Janssens, "Actief in de digitale leeromgeving - didactische scenario's voor een innoverende praktijk" (Active in the digital learning environment: didactic scenarios for an innovative practice), 2010, Plantyn, Mechelen, Belgium (in Dutch).

[4] J. Peuteman, A. Janssens, R. De Craemer, J. Boydens, A. Zabasta, A. Fedotov, "Integration of the European bachelor master degree concept at Belarusian universities for physics and engineering students", Proceedings of the XXV International Scientific Conference Electronics ET2016, pp. 47 - 50, September 12 - 14, 2016, Sozopol, Bulgaria.

[5] D. Hill, "Learning outcomes", Professional Safety, vol. 57, no. 10, pp. 53 - 61, 2012.

[6] F. Dochy, L. Mc. Dowell, "Introduction - Assessment as a Tool for Learning", Studies in Educational Evaluation, vol. 23, no. 4, pp. 279 - 298, 1997.

[7] D. Kirkpatrick, "Evaluating training programs: the four levels", 1994, Berrett-Koehler, San Francisco, USA.

[8] J. Phillips, "How much is the training worth?", Training and Development, vol. 50, no. 4, pp. 2024, 1996.

[9] Testing and Curricula Reports, "The improvement of master-level education in the field of physical sciences in Belarusian universities (Physics)", ERASMUS+, retrieved from URL: https://dl.bsu.by/mod/folder/view.php?id=22838

[10] J. Peuteman, A. Janssens, R. De Craemer, H. Hallez, P. Coudeville, C. Cornelly, A. Maricau, A. Degraeve, G. Strypsteen, P. Rauwoens, A. Zabasta, "Realizing an international student exchange program for Belarusian engineering students to Belgium", $45^{\text {th }}$ SEFI Conference, pp. 1142 - 1149, September 18 - 21, 2017, Azores, Portugal. 